\title{
Regulation of the Human Delta-Opioid Receptor by Alkaloids: Different Roles of Arrestins
}

Elise Camacho ${ }^{1}$, Benjamin Aguila², Nicolas Elie ${ }^{3}$, Jana Sopkova ${ }^{4}$, Caroline Martel ${ }^{1}$, Audrey Davis ${ }^{1}$, Cédric Lecoutey ${ }^{4}$ and Stéphane

Allouche ${ }^{1 *}$

${ }^{1}$ Normandie Univ, Laboratoire de Signalisation, électrophysiologie et imagerie des lésions d'ischémie-reperfusion, EA 4650, 14032 Caen, France

${ }^{2}$ Department of Pharmacology, Center for Addiction and Mental Health, University of Toronto, ON, Canada

${ }^{3}$ Plateau d'Histo-Imagerie Quantitative, CMABIO, Université Caen, Basse-Normandie, Caen, France

${ }^{4}$ Centre d'Etudes et de Recherche sur le Médicament de Normandie - UPRES, EA 4258 - FR CNRS 3038 INC3M, SF 4206 ICORE, Université Caen, Basse-Normandie,

Caen, France

\begin{abstract}
Study background: We previously revealed that the arrestin 2 was differentially involved in the regulation of the human delta opioid receptor (hDOR) by peptidic and alkaloid agonists. In the present study, we examined whether i) hDOR regulation by two related alkaloid agonists (etorphine and morphine) involved the same arrestins ii) similar arrestin-dependent mechanisms occur upon short- and long-term agonist exposure.
\end{abstract}

Methods: The human neuroblastoma SK-N-BE cells, endogenously expressing hDOR, were transfected with wild-type or mutant arrestins. Using shRNA, we also generated a clonal cell line depleted in arrestin 2, the only arrestin isoform expressed in this cell line. Cells were then exposed or not to either morphine ou etorphine for short$(1 \mathrm{~h})$ or long-term $(18 \mathrm{~h})$, then receptor desensitization was examined on the cAMP pathway and internalization was visualized by confocal microscopy.

Results: In arrestin 2-depleted cells, we observed a strong reduction of desensitization after $18 \mathrm{~h}$ of morphine exposure but not with etorphine. Over-expression of wild-type or mutant arrestins produced an opposite modulation of receptor desensitization induced by morphine and etorphine both upon short- and long-term exposure. Confocal fluorescence microscopy experiments did not reveal any strong impact on receptor internalization when different arrestins were over-expressed.

Conclusion: Our results showed that i) two related opioid alkaloid agonists produce hDOR desensitization by different mechanisms ii) the involvement of arrestins in hDOR desensitization depends on the duration of agonist exposure.

Keywords: Arrestin; Camp pathway; Desensitization; Internalization; Morphine; Opioid receptor

Abbreviations: Arr 2: Arrestin 2 (or beta-arrestin 1); Arr3: Arrestin 3 (or beta-arrestin 2); Deltorphin I: Tyr-D-Ala-Phe-Asp-Val-Val-Gly. $\mathrm{NH}_{2}$; DPDPE: D-Penicillamine(2,5)-enkephalin; GPCRs: G proteincoupled receptors; hDOR: Human delta-opioid receptor; KO: Knockout; MOR: Mu opioid receptor; shRNA: Short hairpin RNA

\section{Introduction}

It is well admitted that the opioid system plays a central role in pain control but sustained exposure to exogenous opioids such as morphine that are used for their analgesic properties provokes tolerance in human and in animal (see for review) [1]. Tolerance that is defined by a decrease of the drug response following acute or chronic exposure, is closely related to opioid receptor desensitization observed in vitro. Mechanisms of both tolerance and desensitization have been extensively studied and appeared complex but arrestins were suggested to have a pivotal role as previously reviewed [2]. In arrestin 3-knock out (KO) mice, mu opioid receptor (MOR) desensitization and tolerance were decrease upon chronic morphine exposure compared to wild-type (WT) mice $[3,4]$. Those data are in good agreement with the canonical model of G protein-coupled receptors (GPCRs) regulation, including opioid receptors, indicating that arrestins are negative regulators of signaling by promoting uncoupling and endocytosis of cell surface receptors [5]. There is now accumulating evidence showing that opioid receptors are differentially regulated upon opioid agonist activation (see for review) [6]. This was demonstrated for interactions between DOR and MOR with $G$ proteins and arrestins $[7,8]$. While different ligands could bind to opioid receptors, several laboratories, including ours, reported difference in their ability to regulate such receptors [9-13]. So, in the present study, we adressed the role of arrestins in hDOR regulation upon short- and long-term activation by two related alkaloid agonists morphine and etorphine. This study was conducted in the SK-N-BE cells, endogenously expressing hDOR [14,15]. To answer to those questions, we studied both desensitization, on the cAMP pathway, and receptor internalization in a cellular context overexpressing WT or mutant arrestins or in arrestin-depleted cells.

\section{Material and Methods}

\section{Cell culture}

SK-N-BE cells were maintained in Dulbecco's modified Eagle's medium (DMEM) (Sigma, Saint-Quentin Fallavier, France),

\footnotetext{
*Corresponding author: Stéphane Allouche, Normandie Univ, Laboratoire de Signalisation, électrophysiologie et imagerie des lésions d'ischémie-reperfusion, EA 4650, 14032 Caen, France, Tel: +33231065419; Fax: +33231065172; E-mail: stephane.allouche@unicaen.fr

Received September 03, 2015; Accepted September 21, 2015; Published September 28, 2015

Citation: Camacho E, Aguila B, Elie N, Sopkova J, Martel C, et al. (2015) Regulation of the Human Delta-Opioid Receptor by Alkaloids: Different Roles of Arrestins. Neurochem Neuropharm Open Access 1: 101.

Copyright: (c) 2015 Camacho E, et al. This is an open-access article distributed under the terms of the Creative Commons Attribution License, which permits unrestricted use, distribution, and reproduction in any medium, provided the original author and source are credited.
} 
supplemented with $10 \%$ fetal calf serum (FCS) (Biowest Nuaille, France), $1 \%$ antibiotic-antimycotic mixture (Sigma), and $2 \mathrm{mM} \mathrm{L}$-glutamine at $37^{\circ} \mathrm{C}$ in a water-saturated atmosphere containing $5 \% \mathrm{CO}_{2}$

\section{Plasmids and transfection}

Plasmids containing arrestin 2-GFP, arrestin 3-GFP, arrestin $2^{319-418}$ GFP, R169E arrestin 2-GFP, FLAG-tagged hDOR were kindly provided by Prof. S. Cotecchia (Université de Lausanne, Switzerland), Dr. A. Benmerah (Institut Cochin, Inserm U1016, UMR 8104, Université Paris-Descartes, France) Prof. N.W. Bunnett (University of California, San Francisco, USA), Prof. V.V. Gurevich (Vanderbilt University medical center, Nashville, USA), and Prof. M. Bouvier (Université de Montréal, QC, Canada), respectively. Transfection and the generation of the different clonal cell lines were previously described [16,17]. The different clonal cell lines were cultured under selection using $1 \mathrm{mg} \cdot \mathrm{ml}^{-1}$ geneticin (G418, Sigma Aldrich).

\section{Western blotting}

Expression of WT and mutant arrestins and the inhibition of the endogenous arrestin 2 expression by shRNA was evaluated by westernblot as previously reported [17]. Whole cell lysates were prepared from wild-type SK-N-BE cells and the clonal cell lines. Cells were harvested by centrifugation $(100 \mathrm{~g}, 5 \mathrm{~min})$ and suspended in lysis buffer (10 mM Tris-HCl, 1 mM EDTA, 0.1\% (v/v) Triton-X100, pH 7.4), then sonicated. After a centrifugation $\left(15 \mathrm{~min}\right.$ at $20,000 \mathrm{~g}$ and $\left.4^{\circ} \mathrm{C}\right)$, protein concentration from the supernatant was determined by the Bradford assay and equal amounts were separated on $10 \%(\mathrm{w} / \mathrm{v})$ acrylamide gels by SDS-PAGE. After electroblotting, nitrocellulose membranes were incubated with anti-arrestin 2 and 3 antibody (kindly provided by Prof. S.A. Laporte, McGill University, QC, Canada) followed by peroxidasecoupled secondary antibodies. Proteins were visualized by enhanced chemiluminescence system (Super-Signal West Pico, Pierce, Illkirch, France).

\section{Binding experiments}

Radioligand binding studies were performed on attached cells using $\left[{ }^{3} \mathrm{H}\right]$ diprenorphine as described previously [18]. This radioligand is a lipophilic antagonist that binds both cell surface and intracellular receptors. Cells were seeded in 24-well plates at a density of 100,000 cells/well and were allowed to grow for $48 \mathrm{~h}$. Before binding experiments, cells were washed with DMEM/20 mM Hepes for $5 \mathrm{~min}$ and then incubated for $30 \mathrm{~min}$ at $37^{\circ} \mathrm{C}$ with appropriate concentrations of $\left[{ }^{3} \mathrm{H}\right]$ diprenorphine $(0.05-5 \mathrm{nM})$ in a $0.3-\mathrm{ml}$ final volume of $50 \mathrm{mM}$ Tris- $\mathrm{HCl} / 1 \%$ BSA (w/v), $\mathrm{pH}$ 7.4. Total and nonspecific binding were determined in the absence or in the presence of $20 \mu \mathrm{M}$ levorphanol, respectively. The medium was rapidly removed and cells were harvested in $200 \mu \mathrm{l}$ of $1 \mathrm{~N} \mathrm{NaOH}$ and placed into vials in the presence of $3 \mathrm{ml}$ of scintillation cocktail (PerkinElmer Life and Analytical Sciences). Each determination was carried out in triplicate. Scatchard analysis (supplemental data) was performed using SigmaPlot software to calculate the dissociation constant $K d(\mathrm{nM})$ and the receptor maximum binding capacity $B \max$ (fmol. $\mathrm{mg}^{-1}$ of protein) values.

\section{Measurement of intracellular cAMP}

Inhibition of adenylyl cyclase was determined by measuring $\left[{ }^{3} \mathrm{H}\right]$ cAMP accumulation as previously described [18]. Cells were seeded in 24-well plates at a density of 50,000 cells per well in a culture medium supplemented with $0.6 \mathrm{mCi}\left[{ }^{3} \mathrm{H}\right]$ adenine and incubated overnight. cAMP accumulation was determined in the presence of isobutylmethylxanthine, forskolin and in the absence or in the presence of agonists. After $5 \mathrm{~min}$ at $37^{\circ} \mathrm{C}$, the reaction was stopped by addition of $5 \%(\mathrm{w} / \mathrm{v})$ trichloroacetic acid. The $\left[{ }^{3} \mathrm{H}\right]$ cAMP content of each well was isolated by chromatography on acid alumina columns, mixed with $8 \mathrm{ml}$ of scintillation mixture (Pico- Fluor-40, PerkinElmer), before assaying in a scintillation counter (PerkinElmer). Maximal inhibitory levels of opioid agonists were determined for each clonal cell line at $0.1 \mathrm{X}, 1 \mathrm{X}$ and $10 \mathrm{X}$ where $\mathrm{X}$ corresponds to the concentration producing the maximum response in the WT SK-N-BE cells SK-N-BE cells $[11,19]$. For desensitization experiments, cells were pretreated or not (naïve) either for 1 or $18 \mathrm{~h}$ with the concentration of etorphine or morphine producing the maximal inhibition of cAMP accumulation in each clonal cell line (Table 1 ). Then, the hDOR-induced adenylyl cyclase inhibition was measured for $5 \mathrm{~min}$ at $37^{\circ} \mathrm{C}$ without removing the medium to avoid adenylyl cyclase superactivation in the presence of $1 \mathrm{mM}$ isobutylmethylxanthine alone (basal activity) or in combination with $40 \mu \mathrm{M}$ forskolin (FSK) (stimulated activity). We checked that addition of freshly prepared agonist (etorphine or morphine) after 1 or $18 \mathrm{~h}$ exposure did not promote additional inhibition of cAMP accumulation demonstrating that the reduction of cAMP inhibition was due to hDOR desensitization and not agonist degradation. All experiments were carried out in triplicate and repeated at least three times with similar results.

\section{Internalization studies by confocal microscopy}

Localization of both hDOR (red) and arrestins (green) were visualized as described previously [17]. For image analysis, the freeware Image $1.47 \mathrm{v}$ was used to quantify the cell surface receptors (http:// imagej.nih.gov/ij). We determined the integrated density of cell surface labeling using the TRITC channel both in GFP-positive and negative cells.

\section{Docking studies}

For each docked compound a preliminary calculation on its protonation state at $\mathrm{pH} 7.4$ was carried out using standard tools of the ChemAxon Package (http://www.chemaxon.com/) and the majority microspecies protonated on nitrogen (corresponding to among $98 \%$ for morphine as well as for etorphine) at this $\mathrm{pH}$ was used for docking studies. The crystallographic coordinates of hDOR used for docking studies were obtained from X-ray structure of the naltrindole/deltaopioid receptor complex (PDB ID 4N6H, a structure refined to $1.8 \AA$ with an $\mathrm{R}$ factor of 17.3\%) [20]. Docking of morphine and etorphine into hDOR was carried out by means of the GOLD program with the default parameters [21]. This program applies a genetic algorithm to explore conformational spaces and ligand binding modes. To evaluate the proposed ligand poses, the ChemPLP, GoldScore and ChemScore fitness functions were applied (see the scores in supplemental data). The binding site in the hDOR model was defined as a $10 \AA$ sphere from the co-crystallized ligand natrindole using the detection cavity algorithm.

\section{Statistical analysis}

All results are expressed as the mean \pm standard error of the mean (S.E.M.) of $n$ experiments. ANOVA (Graphpad Prism 4.0 ${ }^{\mathrm{m}}$ ) followed either by the Dunnett or the Bonferroni Test or Student t-test, when appropriate, were used to determine the statistical significance.

\section{Results}

\section{Expression of WT or mutant arrestins in SK-N-BE cells}

Stable expression of arrestins 2 or 3 , the constitutively active mutant R169E arrestin 2 or a dominant negative (DN) mutant (arrestin $2^{319}$ 
$\left.{ }^{418}\right)$, all fused to the green fluorescent protein (GFP), was obtained at the expected size in the clonal cell lines when the BE-WT cells endogenously expressed only the arrestin 2 at about $50 \mathrm{kDa}$ (Figure 1A). Arrestin 2-GFP and the DN mutant-GFP were expressed almost to the same level as the endogenous arrestin 2 while the R169E arrestin 2-GFP and arrestin 3-GFP were expressed to a lower level (data not shown). A significant depletion of the endogenous arrestin 2 was also obtained by transfection of a specific shRNA compared to a mismatch sequence (MM) (Figure 1B).

\section{Short- and long-term hDOR desensitization promoted by etorphine or morphine}

Then, we examined the impact of arrestin over-expression or $\mathrm{KO}$ of endogenous arrestin 2 on the endogenous hDOR level and the ability of both morphine and etorphine to inhibit adenylyl cyclase. We showed no significant modifications of $B_{\text {max }}$ values while over-expression of arrestin 3-GFP slightly but significantly increase de $\mathrm{Kd}$ value by about 3 -fold (Table 1). In functional studies, we observed that arrestin 3-GFP overexpression and $\mathrm{KO}$ of endogenous arrestin 2 significantly decreased the maximal inhibition produced by etorphine while the production of MM sequence increased morphine-induced cAMP inhibition and the dominant negative mutant of arrestin reduced morphine potency (Table 2). Then, we selected concentrations of etorphine and morphine producing almost similar and maximal inhibition of adenylyl cyclase to promote hDOR desensitization after short- and long-term exposure in the various clonal cell lines. The inhibition of cAMP accumulation produced by each agonist was normalized to $100 \%$ in control (Figure $2 \mathrm{~A}$ and $2 \mathrm{~B}$ ). In the BE-WT cells, $1 \mathrm{~h}$ exposure to either etorphine or morphine produced a similar level of desensitization by about $65 \%$
(Figure 2A and 2B). When the different clonal cell lines were pretreated with etorphine for $1 \mathrm{~h}$, only the over-expression of arrestin 2-GFP was shown to significantly potentiate hDOR desensitization $(63.7 \pm 4.4 \%$ for BE-WT vs $94.4 \pm 5.7 \%$ for arrestin 2-GFP) (Figure 2A). Surprisingly, morphine-induced hDOR desensitization was significantly decreased when either arrestin 3-GFP or R169E arrestin 2-GFP were expressed compared to BE-WT cells (Figure $2 \mathrm{~B}$ ). After $18 \mathrm{~h}$ pretreament of BE-WT cells with morphine, we observed a superactivation of adenylyl cyclase by $50 \%$ while etorphine promoted a complete desensitization (Figure $2 \mathrm{C}$ and $2 \mathrm{D}$ ). Only the over-expression of arrestin 2-GFP significantly increased hDOR desensitization upon long-term etorphine treatment which was evidenced by a superactivation of adenylyl cyclase (Figure 2C). In contrast, when WT and mutant of arrestins were over-expressed we rather observed a decrease in adenylyl cyclase superactivation after $18 \mathrm{~h}$ morphine exposure (Figure 2D). When endogenous arrestin 2 expression was impaired by shRNA, we observed a major reduction of desensitization by comparison with the MM clonal cell line but only upon morphine treatment (Figure 2D).

\section{Etorphine and morphine promote hDOR endocytosis upon short- and long-term exposure}

To study the influence of arrestins on hDOR internalization upon short- and long-term exposure to etorphine or morphine, SK-NBE cells stably expressing the FLAG-tagged hDOR were transiently transfected with WT, mutants of arrestins or shRNA directed against the endogenous arrestin 2. Then, we monitored the FLAG-tagged hDOR (red) and arrestins-GFP (green) localization by confocal microscopy and semi-quantitative analyses were performed by determining plasma

A

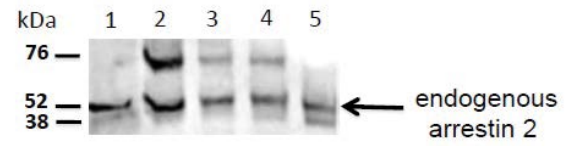

B $\quad \mathrm{kDa} \quad 12$

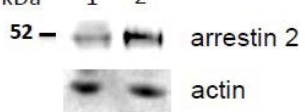

Figure 1: Arrestins expression in the BE-WT and the clonal cell lines. (A) Whole cell lysates were prepared from wild type SK-N-BE cells (lane 1), arrestin 2-GFP (lane 2), arrestin 3-GFP (lane 3), R169E-arrestin2-GFP (lane 4) or the dominant negative mutant arrestin 2319-418-GFP (lane 5) clonal cell lines. (B) Whole cell lysates were also prepared from clonal cell lines expressing shRNA directed against the endogenous arrestin 2 (lane 1) or a mismatch sequence (lane 2). Proteins were resolved by SDS/PAGE and expression of both endogenous and exogenous arrestins as well as actin were determined.

\begin{tabular}{|c|c|c|c|c|c|c|c|c|}
\hline \multicolumn{2}{|c|}{ Agonists } & BE-WT & Arr2-GFP & Arr3-GFP & Arr2 ${ }^{319-418-G F P}$ & R169E Arr2-GFP & shRNA & MM \\
\hline \multirow[t]{2}{*}{ Eto } & $I_{\max } \%$ & $50.2 \pm 2.6^{\$}$ & $42.6 \pm 3.7^{\$}$ & $27.3 \pm 0.7^{\text {** }}$ & $55.6 \pm 2.8^{\$}$ & $68.6 \pm 4.8^{* *}$ & $31.3 \pm 5.6^{* \star s}$ & $51.1 \pm 2.8^{\$}$ \\
\hline & [L] M & $10^{-7 \$}$ & $10^{-7 \$}$ & $10^{-7}$ & $10^{-7 \$}$ & $10^{-7}$ & $10^{-7 \$}$ & $10^{-7 \$}$ \\
\hline \multirow[t]{2}{*}{ Mor } & $\mathrm{I}_{\max } \%$ & $43.0 \pm 4.6$ & $37.7 \pm 3.4$ & $46.1 \pm 7.4$ & $45.8 \pm 4.5$ & $42.4 \pm 3.3$ & $35.9 \pm 1.1$ & $55.0 \pm 5.9^{*}$ \\
\hline & [L] M & $10^{-5}$ & $10^{-5}$ & $10^{-5}$ & $10^{-4^{*}}$ & $10^{-5}$ & $10^{-5}$ & $10^{-5}$ \\
\hline
\end{tabular}

Table 1: Etorphine and morphine promote adenylyl cyclase inhibition in the different clonal cell lines. The concentration [L] and the maximum cAMP inhibition (I ) produced by etorphine (Eto) and morphine (Mor) were determined in the BE-WT and in the different clonal cell lines. Data are the means \pm S.E.M of 3-5 independent experiments performed in triplicate. Significance compared to BE-WT cells is indicated: ${ }^{*}, \mathrm{P}<0.05$ or ${ }^{* *}, \mathrm{P}<0.01$, One-way ANOVA followed by Dunnett's multiple comparison tests. ${ }^{\$}$, data published in ref. [17].

\begin{tabular}{|l|c|c|c|c|c|c|}
\hline & BE-GFP & Arr2-GFP & Arr3-GFP & Arr2 ${ }^{319-418}$-GFP & R169E Arr2-GFP & shRNA \\
\hline Bmax (fmol.mg-1) & $70.9 \pm 2.9$ & $90.9 \pm 3.1$ & $92.5 \pm 9.0$ & $83.5 \pm 15.0$ & $90.8 \pm 8.9$ & $88.2 \pm 1.0$ \\
\hline Kd (nM) & $0.42 \pm 0.03$ & $0.55 \pm 0.22$ & $1.56 \pm 0.38^{*}$ & $0.20 \pm 0.08$ & $0.35 \pm 0.06$ & $1.01 \pm 0.33$ \\
\hline
\end{tabular}

Table 2: Endogenous hDOR level in the different clonal cell lines. Endogenous hDOR expression was determined in the different clonal cell lines. Data are means $\pm S . E . M$. of 2-3 different experiments performed in triplicate. Significance compared to BE-GFP cell line is indicated: *, P<0.05, One-way ANOVA followed by Dunnett's multiple comparison tests. 
membrane labelling using Image J as previously reported [22]. In naïve cells transfected $\left(\mathrm{GFP}^{+}\right)$or not $\left(\mathrm{GFP}^{-}\right)$with the different plasmids containing the WT or the mutants of arrestins, the hDOR was mainly localized at the plasma membrane (Figure 3, naïves). When cells were pretreated either with etorphine or morphine for $1 \mathrm{~h}$, we observed a strong internalization of the opioid receptor Figure 3, Eto $1 \mathrm{~h}$ and Mor 1h) without any significant effect of arrestin expression (Figure 4). In the shRNA clonal cell line, we showed that decrease of endogenous arrestin 2 expression significantly reduced etorphine-induced hDOR internalization while it increased receptor internalization in the case of morphine but very slightly Figure 4, Eto $1 \mathrm{~h}$ and Mor $1 \mathrm{~h}$ ). When the time of pretreatment was extended to $18 \mathrm{~h}$, we observed a strong decrease of hDOR immunolabeling for both alkaloid agonists (Figures 3 and 4) without any significant difference between $\mathrm{GFP}^{+}$and GFP- except in the dominant negative mutant clonal cell line where morphine-induced hDOR endocytosis was significantly but slightly decreased (Figure 4, Mor 18h).

\section{Discussion}

The present study showed that arrestins produced a different hDOR regulation upon activation by two related alkaloid agonists, etorphine and morphine. Upon short-term exposure, both agonists promote an arrestin-independent desensitization and internalization as demonstrated in shRNA cell line. While this result contrasts with the canonical model of GPCR regulation, previous reports also showed the lack of arrestin implication in morphine-induced MOR desensitization $[23,24]$. This is unlikely due to an absence of a total inhibition of arrestin 2 expression by shRNA since we previously reported the role of this protein in DPDPE- and deltorphin I-mediated hDOR desensitization using the same clonal cell line [17]. Those data clearly show that upon short-term exposure morphine and etorphine, on one hand, and DPDPE and deltorphin I, on the other hand, are biased agonists at the hDOR to recruit arrestin 2 for desensitization. Receptor desensitization could be due to sequestration as previously demonstrated for etorphine [18] but involvement of other actors such as RGS [25] or kinases [26] cannot be ruled out. Since expression of exogenous WT or mutant of arrestins were not equivalent between the different clonal cell lines (Figure 1) and over-expression of arrestins could affect the binding properties of hDOR (decrease of affinity by arrestin 3-GFP) (Table 2 ), their comparison would therefore be misleading. The increase of $K_{d}$ value observed in the arrestin 3-GFP clonal cell line could explain the decrease of the maximal inhibitory effect of etorphine; but this was not detected upon morphine treatment. Furthermore, reduction of endogenous level of arrestin 2 also decreased the $I_{\text {max }}$ value for etorphine indicating that modulation of endogenous and exogenous arrestin levels had a complex impact on hDOR. However, in a given clonal cell line, comparison between the two alkaloid agonists is possible. When over-expressing arrestins, we observed their differential involvement in etorphine- and morphine-induced receptor desensitization. In a cellular context of arrestin 2 over-expression, we showed an increase of receptor desensitization both at short- and long term exposure only for etorphine suggesting a poor interaction between those proteins that could be overcome by increasing the level of arrestin 2. This weak interaction is not related to the lack of receptor phosphorylation since etorphine enhanced Ser363 phosphorylation and promoted a GRK2-dependent desensitization [26]. In constrast, arrestin 2 was unable to promote receptor short-term desensitization upon morphine exposure even when its level was over-expressed. This indicates that the conformation of the receptor-morphine complex would be a poor substrate for arrestin 2 binding. When considering

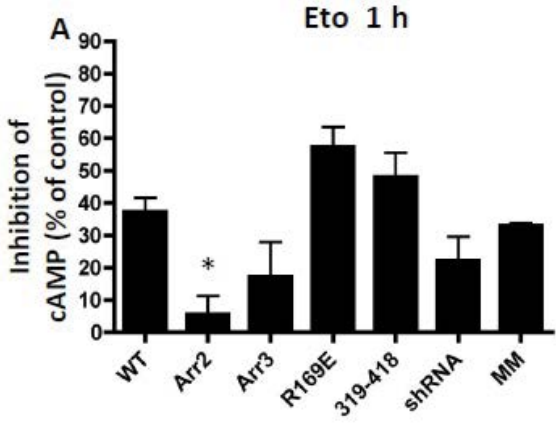

Eto $18 \mathrm{~h}$

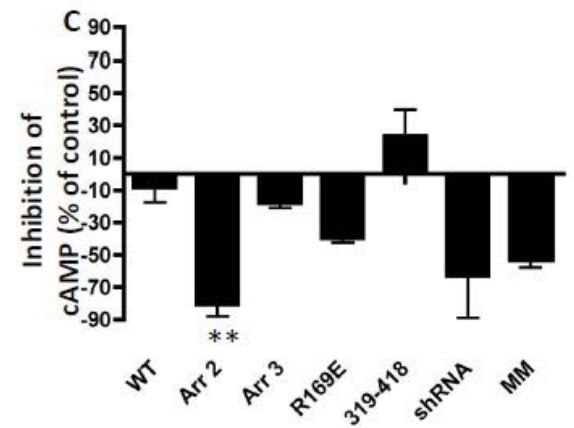

B

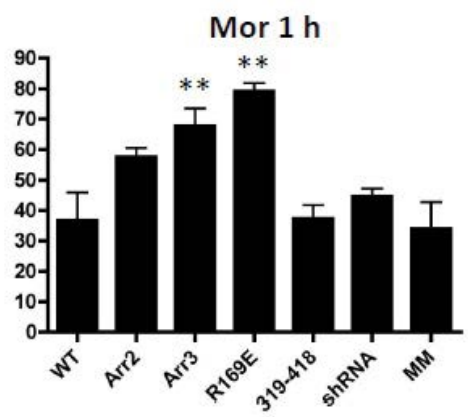

Mor $18 \mathrm{~h}$

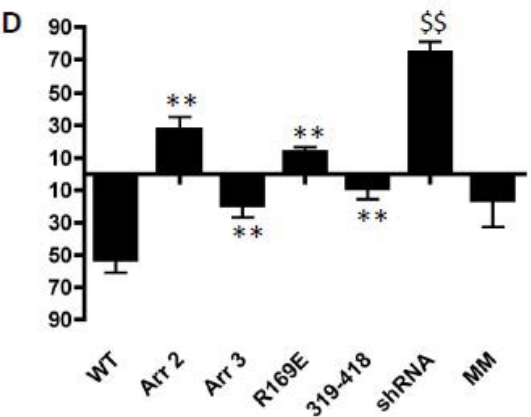

Figure 2: Role of arrestins in short- and long-term desensitization of hDOR. Wild type SK-N-BE cells and the different clonal cell lines were pretreated or not (naïve) for 1 or $18 \mathrm{~h}$ with etorphine (A and $C$, Eto) or morphine (B and D, Mor). Agonist-induced inhibition of cAMP in naïve cells was referred as $100 \%$. Data are means \pm S.E.M. of 3-9 different experiments performed in triplicate. ${ }^{*}, \mathrm{P}<0.05$ and ${ }^{*}$, $\mathrm{P}<0.01$, one-way ANOVA followed by Dunnett's test compared to BE-WT cells, $\$ \$, P<0.01$, t-test compared to shRNA MM. 


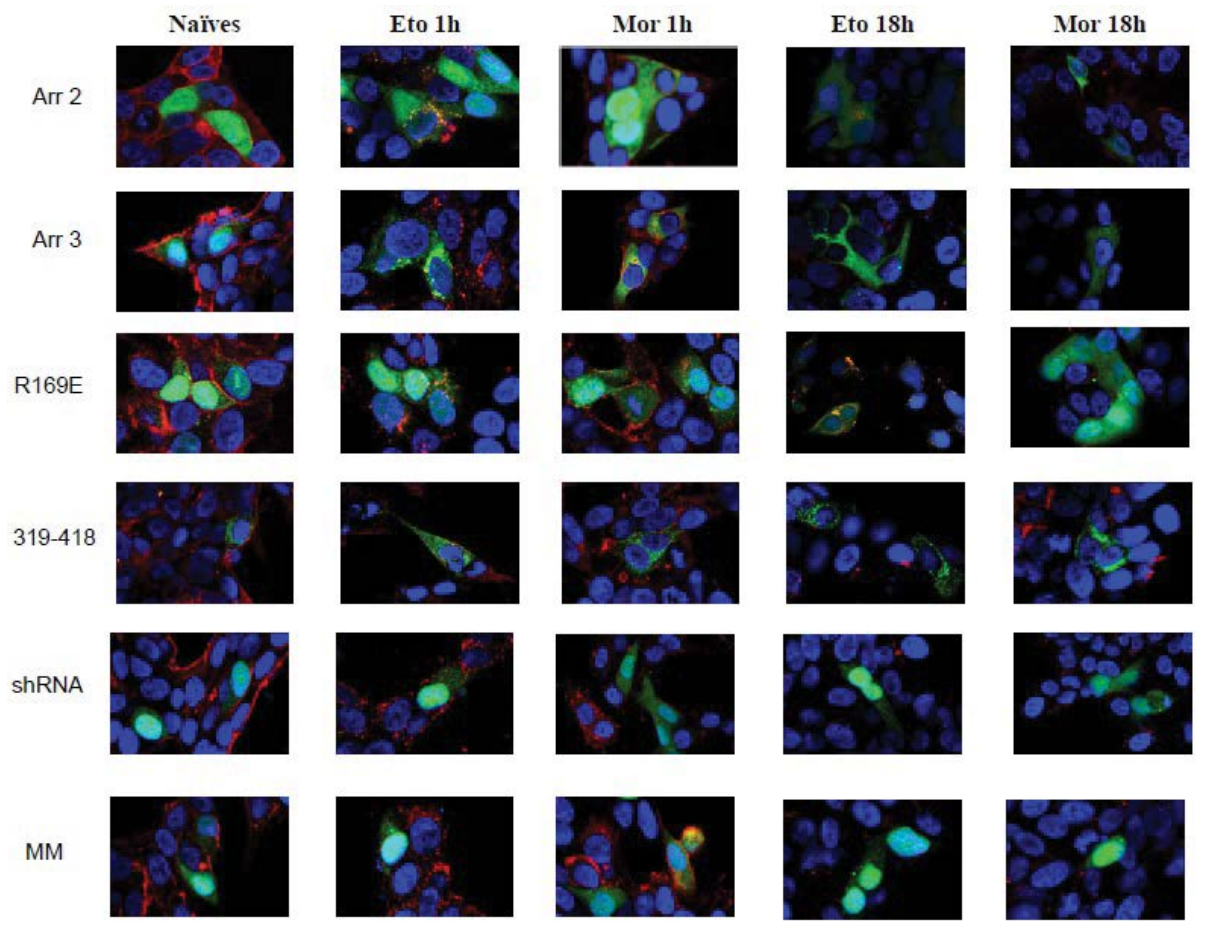

Figure 3: Role of arrestins in hDOR internalization. SK-N-BE cells stably over-expressing the FLAG-tagged hDOR were transiently transfected with arrestin 2-GFP (Arr 2), arrestin 3-GFP (Arr 3), the constitutively active mutant R169E-arrestin2-GFP (R169E), the dominant negative mutant arrestin $2^{319-418}$-GFP (319418), a plasmid producing both GFP and shRNA directed against the endogenous arrestin 2 (shRNA) or a mismatch sequence (MM). Cells were treated or not (naïve) with etorphine (Eto) or morphine (Mor) for either 1 or $18 \mathrm{~h}$. After treatment, cells were fixed and immunostained with the anti-FLAG M2 antibody. Immunoreactivity was revealed with a TRITC-conjugated secondary antibody. Localization of the hDOR (in red) and arrestins or shRNA (in green) was observed by confocal microscopy at a $60 \mathrm{X}$ lens. Images are representative of 3 to 4 independent experiments.

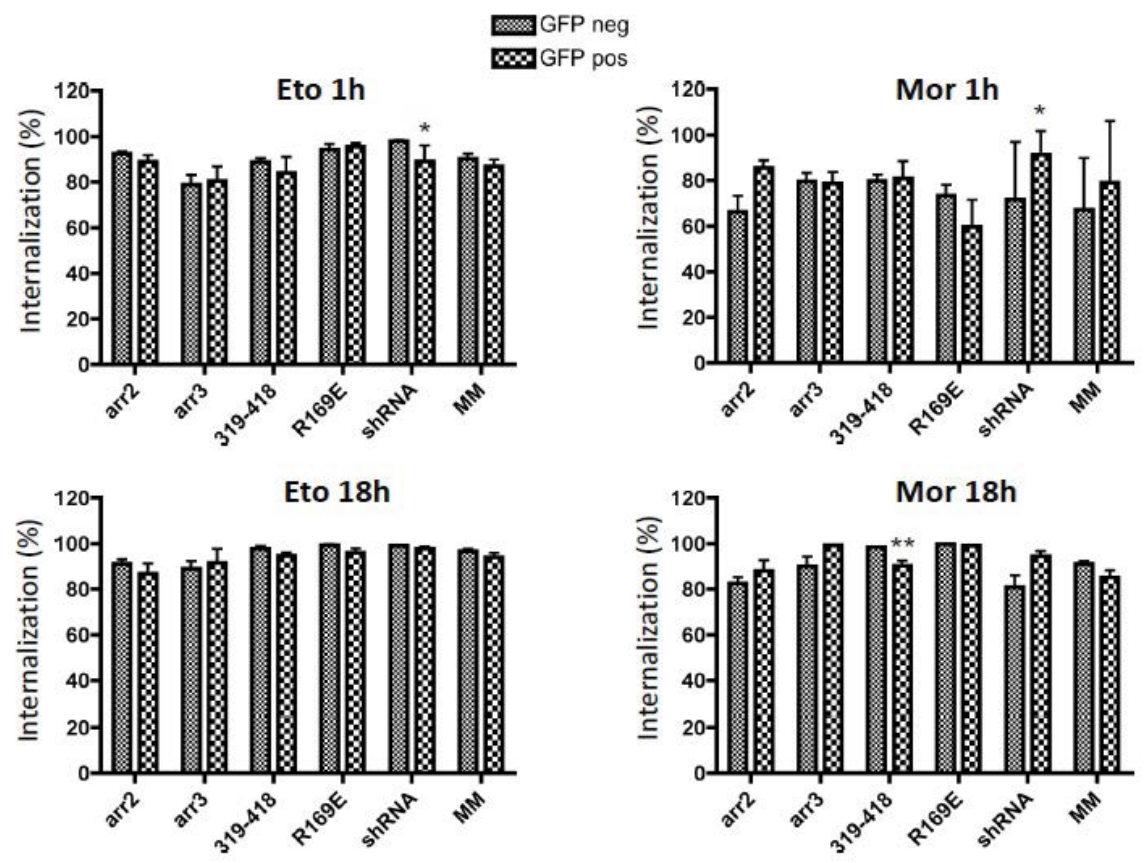

Figure 4: Quantification of hDOR internalization. Integrated density corresponding to cell surface hDOR labelling was determined as described in Material and Methods both in GFP-positive (expressing WT or mutant of arrestins or shRNA) and negative cells (non-transfected cells). Data are means \pm S.E.M. of 3 independent experiments. ${ }^{\star *}, \mathrm{P}<0.01,{ }^{* \star *}, \mathrm{P}<0.001$, two-way ANOVA followed by Bonferroni's test compared to GFP-negative cells. 

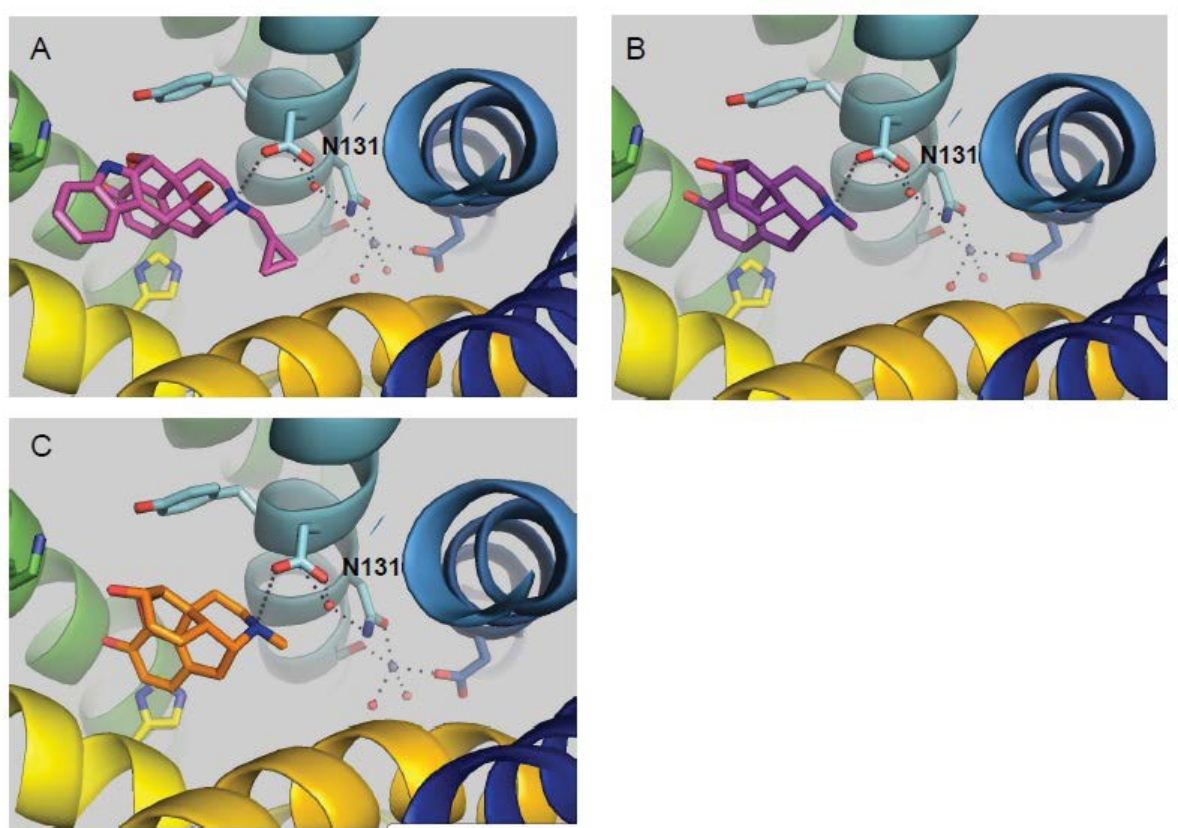

Figure 5: Modeling of naltrindole, etorphine and morphine binding on hDOR. X-ray structure of naltrindole co-crystallized with the hDOR (A) in comparison with docking configurations of morphine $(B)$ and etorphine $(C)$. The ligands and selected side chains are shown in the stick representation and the sodium ion (purple) and selected water molecules (red) are shown as balls. Polar interactions are presented as dash-lines. This figure was made with PYMOL v1.3 (DeLano Scientific, 2002, San Carlo, USA).

short-term activation, we showed that arrestin 3 and the constitutively active mutant inhibit receptor desensitization upon morphine but not etorphine exposure probably by promoting a significant hDOR internalization and recycling as previously demonstrated [27]. Morphine, but not etorphine, would promote conformational receptor changes that could enable efficient interactions between the hDOR and the arrestin 3 or the constitutively active mutant. Such a preferential interaction between $\mathrm{hDOR}$ and arrestin 3 under morphine activation compared to etorphine was not previously observed [8]. However, it is highly difficult to compare our data with this study since those authors over-expressed hDOR to a level about 100 to 200 -fold higher than in our cellular model and failed to detect any significant interaction between the hDOR and arrestin 2-GFP. Furthermore, it is well admitted that receptor over-expression increases spare receptors which consequently reduced desensitization [28]. The great difference in receptor expression (and in spare receptors) between our study and others could be a major factor to explain discrepancies about the role of arrestin in the desensitization process. While our data do not support any role of arrestin 3 in hDOR regulation, others showed that this protein preferentially interacts with $\mathrm{mDOR}$ [29] and promotes the mouse receptor desensitization [30]. Such discrepancy would be related to the substantial differences in the carboxy-terminal tail between the mouse and the human DOR, a critical region for interactions with arrestins [31]. After long-term agonist exposure, we observed a complete desensitization or a slight increase in adenylyl cyclase activity for morphine pretreatment. This was correlated with a global decrease of DOR immuno-reactivity. Prolonged activation of DOR by morphine or etorphine was reported to cause receptor down-regulation in different brain regions $[32,33]$ and also in the SK-N-BE cell line in the case of etorphine [18,34]. When examining the potential role of arrestins in long-term receptor regulation, we found that decrease of endogenous arrestin 2 expression greatly reduced desensitization induced by morphine but not by etorphine. This indicates that i) hDOR desensitization would involve different molecular mechanisms upon short- and long-term treatment by morphine ii) etorphine and morphine, two related alkaloid agonists, induce desensitization but via different mechanisms implicating or not the arrestin 2. Interestingly, morphine (see for review) [35] and etorphine [26] were shown to promote acute desensitization of opioid receptors in a PKC-dependent manner. So, we can hypothesize that in such conditions arrestins would not be required. However, under long-term activation, morphine would promote a significant hDOR phosphorylation to enable the recruitment of arrestin 2 . The reduction of hDOR desensitization observed after $18 \mathrm{~h}$ morphine exposure in arrestin 2-depleted cells is not related to a decrease of receptor internalization. This is not surprising since previous studies reported no correlation between opioid receptor internalization and desensitization [19,36]. This also suggests that very few cell surface receptors would enable an almost complete inhibition on the cAMP pathway and/or confocal microscopy is not an accurate tool to detect few receptors in such conditions. Furthermore, evaluation of hDOR level by binding experiments and immunolabeling showed discrepancies indicating that the two methods have their own limitations and require a careful interpretation. Rather than a classical role in uncoupling and internalization, our data suggest that arrestin 2 would inhibit recycling and resensitization upon longterm morphine treatment as recently demonstrated for the MOR and arrestin 3 [37]. As observed for short-term pretreatment, arrestin 2 over-expression potentiates DOR desensitization upon $18 \mathrm{~h}$ etorphine which was characterized by a superactivation of adenylyl cyclase ; this confirms that arrestin 2 is the preferred partner of the hDOR when activated by etorphine but not morphine. Concerning long-term morphine exposure, over-expression of either WT or mutant arrestins was shown to decrease adenylyl cyclase superactivation. Recent data 
indicate that Src mediated-MOR phosphorylation would recruit Ras/ Raf-1 proteins which in turn increase adenylyl cyclase activity $[38,39]$. Over-expression of arrestins, which were shown to interact with Src [40], could interfere with such tyrosine phosphorylation and inhibit adenylyl cyclase superactivation.

Recently, Fenalti et al. identified in the crystal structure of the hDOR that the sodium ion and Asn131 played a major role in the constitutive activation of arrestin [20]. So, we hypothesized that morphine or etorphine could differentially modify the interaction network around sodium and/or Asn131 favouring arrestin interactions. However, based on the high resolution hDOR structure bound to naltrindole, our in silico analysis failed to reveal any significant modification at Asn131 upon either morphine or etorphine binding (Figure 5). This latter result does not challenge the biased agonism theory but could rather suggest that other regions of the receptor would be involved in the arrestin interactions. Indeed, several residues of the complex etorphine-mouse DOR were identified by $3 \mathrm{D}$ modeling that could modulate auxillary sites for receptor partners such as arrestins [41]. Furthermore, the carboxy-terminal tail of the DOR, which was not included in the crystal structure, represents a putative region involved in the differential interaction between receptor and arrestins upon etorphine or morphine exposure.

\section{Conclusions}

It is now well admitted that opioid receptor desensitization plays a major role in tolerance. Our study showed that different molecular mechanisms occured in short- and long-term hDOR desensitization upon morphine treatment. While both alkaloid agonists, etorphine and morphine, produced an arrestin 2-independent short-term hDOR desensitization, the endogenous arrestin 2 would rather inhibit recycling and potentiate desensitization after $18 \mathrm{~h}$ morphine exposure but not for etorphine. Our data also suggest that hDOR would poorly interact with endogenous arrestin 2 but when over-expressing arrestins, we could reveal a different role of WT or mutant arrestin under alkaloid agonists exposure. Our study shows that two closely related opioid agonists promote a complex receptor regulation and supports the notion of arrestin-biased agonism at hDOR.

\section{Acknowledgements}

This work was supported by the ministère de l'enseignement supérieur et de la recherche. Drs. B Aguila and E. Camacho were recipients of the Regional Council of Lower-Normandy and the ANRT (Association Régionale Recherche Technologie), respectively with the financial support of the Elitech group. We thank Professors Cotecchia (University of Lausanne, Switzerland), Benmerah (Institu Cochin, France), Bunnett (University of California, San Francisco), Gurevich (Vanderbilt University medical center, USA), Bouvier (Université de Montréal, Canada) and Laporte (McGill University, QC, Canada) for kindly providing plasmids and the anti-arrestins 2 and 3 antibody. The authors would like to thank Dr Nicolas Marie (Université Paris Descartes, France) for helpful discussions and critical reading of the manuscript.

\section{References}

1. Allouche S, Noble F, Marie N (2014) Opioid receptor desensitization: mechanisms and its link to tolerance. Front Pharmacol 5: 280.

2. Schmid CL, Bohn LM (2009) Physiological and pharmacological implications of beta-arrestin regulation. Pharmacol Ther 121: 285-293.

3. Bohn LM, Lefkowitz RJ, Gainetdinov RR, Peppel K, Caron MG, et al. (1999) Enhanced morphine analgesia in mice lacking beta-arrestin 2. Science 286: 2495-2498.

4. Bohn LM, Gainetdinov RR, Lin FT, Lefkowitz RJ, Caron MG, et al. (2000) Mu-opioid receptor desensitization by beta-arrestin-2 determines morphine tolerance but not dependence. Nature 408: 720-723.
5. Shenoy SK, Lefkowitz RJ (2011) $\hat{I}^{2}$-Arrestin-mediated receptor trafficking and signal transduction. Trends Pharmacol Sci 32: 521-533.

6. Pradhan AA, Smith ML, Kieffer BL, Evans CJ (2012) Ligand-directed signalling within the opioid receptor family. Br J Pharmacol 167: 960-969.

7. McPherson J, Rivero G, Baptist M, Llorente J, Al-Sabah S, et al. (2010) Î1/4opioid receptors: correlation of agonist efficacy for signalling with ability to activate internalization. Mol Pharmacol 78: 756-766.

8. Molinari P, Vezzi V, Sbraccia M, Grò C, Riitano D, et al. (2010) Morphine-like opiates selectively antagonize receptor-arrestin interactions. J Biol Chem 285 12522-12535.

9. Zastrow von M, Keith DE, Evans CJ (1993) Agonist-induced state of the deltaopioid receptor that discriminates between opioid peptides and opiate alkaloids. Mol Pharmacol 44: 166-172.

10. Keith DE, Anton B, Murray SR, Zaki PA, Chu PC, et al. (1998) mu-Opioid receptor internalization: opiate drugs have differential effects on a conserved endocytic mechanism in vitro and in the mammalian brain. Mol Pharmacol 53 377-384.

11. Allouche S, Roussel M, Marie N, Jauzac P (1999) Differential desensitization of human delta-opioid receptors by peptide and alkaloid agonists. Eur J Pharmacol 371: 235-240.

12. Marie N, Landemore G, Debout C, Jauzac P, Allouche S (2003) Pharmacological characterization of AR-M1000390 at human delta opioid receptors. Life Sci 73 1691-1704.

13. Lecoq I, Marie N, Jauzac P, Allouche $S$ (2004) Different regulation of human delta-opioid receptors by SNC-80 [(+)-4-[(alphaR)-alpha-((2S,5R)-4-allyl2,5-dimethyl-1-piperazinyl)-3-methoxybenzyl]-N,N-diethylbenzamide] and endogenous enkephalins. J Pharmacol Exp Ther 310: 666-677.

14. Polastron J, Mur M, Mazarguil H, Puget A, Meunier JC, et al. (1994) SK-N$\mathrm{BE}$ : a human neuroblastoma cell line containing two subtypes of delta-opioid receptors. J Neurochem 62: 898-906

15. Allouche S, Hasbi A, Ferey V, Sola B, Jauzac P, et al. (2000) Pharmacological delta1- and delta2-opioid receptor subtypes in the human neuroblastoma cell line SK-N-BE: no evidence for distinct molecular entities. Biochem Pharmacol 59: 915-925.

16. Aguila B, Roussel M, Jauzac P, Allouche S (2006) High-purity selection and ma intenance of gene expression in human neuroblastoma cells stably over-expressing GFP fusion protein. Application for opioid receptors desensitization studies. Brain Res 1114: 11-18.

17. Aguila B, Coulbault L, Davis A, Marie N, Hasbi A, et al. (2012) ÃŸarrestin1 biased agonism at human $\hat{I}^{\prime}$-opioid receptor by peptidic and alkaloid ligands. Cell Signal 24: 699-707.

18. Marie N, Lecoq I, Jauzac P, Allouche S (2003) Differential sorting of human delta-opioid receptors after internalization by peptide and alkaloid agonists. $J$ Biol Chem 278: 22795-22804

19. Aguila B, Coulbault L, Boulouard M, Léveillé F, Davis A, et al. (2007) In vitro and in vivo pharmacological profile of UFP-512, a novel selective delta-opioid receptor agonist; correlations between desensitization and tolerance. $\mathrm{Br} \mathrm{J}$ Pharmacol 152: 1312-1324.

20. Fenalti G, Giguere PM, Katritch V, Huang XP, Thompson AA, et al. (2014) Molecular control of $\hat{I}^{\prime}$-opioid receptor signalling. Nature 506: 191-196.

21. Jones G, Willett P, Glen RC, Leach AR, Taylor R, et al. (1997) Development and validation of a genetic algorithm for flexible docking. J Mol Biol 267: 727-748.

22. Melief EJ, Miyatake M, Bruchas MR, Chavkin C (2010) Ligand-directed c-Jun $\mathrm{N}$-terminal kinase activation disrupts opioid receptor signaling. Proc Natl Acad Sci U S A 107: 11608-11613.

23. Chu J, Zheng H, Loh HH, Law PY (2008) Morphine-induced mu-opioid receptor rapid desensitization is independent of receptor phosphorylation and betaarrestins. Cell Signal 20: 1616-1624.

24. Dang VC, Napier IA, Christie MJ (2009) Two distinct mechanisms mediate acute mu-opioid receptor desensitization in native neurons. J Neurosci 29 3322-3327.

25. Wang Q, Liu-Chen LY, Traynor JR (2009) Differential modulation of mu- and delta-opioid receptor agonists by endogenous RGS4 protein in SH-SY5Y cells. 
Citation: Camacho E, Aguila B, Elie N, Sopkova J, Martel C, et al. (2015) Regulation of the Human Delta-Opioid Receptor by Alkaloids: Different Roles of Arrestins. Neurochem Neuropharm Open Access 1: 101.

Page 8 of 8

J Biol Chem 284: 18357-18367.

26. Marie N, Aguila B, Hasbi A, Davis A, Jauzac P, et al. (2008) Different kinases desensitize the human delta-opioid receptor (hDOP-R) in the neuroblastoma cell line SK-N-BE upon peptidic and alkaloid agonists. Cell Signal 20: 12091220.

27. Pan L, Gurevich EV, Gurevich VV (2003) The nature of the arrestin x receptor complex determines the ultimate fate of the internalized receptor. J Biol Chem 278: 11623-11632.

28. Connor M, Osborne PB, Christie MJ (2004) Mu-opioid receptor desensitization is morphine different? $\mathrm{Br} \mathrm{J}$ Pharmacol 143: 685-696.

29. Zhang X, Wang F, Chen X, Li J, Xiang B, et al. (2005) Beta-arrestin1 and beta-arrestin2 are differentially required for phosphorylation-dependent and -independent internalization of delta-opioid receptors. J Neurochem 95: 169178

30. Qiu Y, Loh HH, Law PY (2007) Phosphorylation of the delta-opioid recepto regulates its beta-arrestins selectivity and subsequent receptor internalization and adenylyl cyclase desensitization. J Biol Chem 282: 22315-22323.

31. Cen B, Xiong Y, Ma L, Pei G (2001) Direct and differential interaction of betaarrestins with the intracellular domains of different opioid receptors. Mol Pharmacol 59: 758-764.

32. Tao PL, Law PY, Loh HH (1987) Decrease in delta and mu opioid receptor binding capacity in rat brain after chronic etorphine treatment. J Pharmacol Exp Ther 240: 809-816.

33. Turchan J, Przewlocka B, Toth G, Lasoń W, Borsodi A, et al. (1999) The effect of repeated administration of morphine, cocaine and ethanol on mu and delta opioid receptor density in the nucleus accumbens and striatum of the rat. Neuroscience 91: 971-977.
34. Hasbi A, Allouche S, Sichel F, Stanasila L, Massotte D, et al. (2000) Internalization and recycling of delta-opioid receptor are dependent on a phosphorylation-dephosphorylation mechanism. J Pharmacol Exp Ther 293: 237-247.

35. Kelly E, Bailey CP, Henderson G (2008) Agonist-selective mechanisms of GPCR desensitization. Br J Pharmacol 153 Suppl 1: S379-388.

36. Qiu Y, Law PY, Loh HH (2003) Mu-opioid receptor desensitization: role of receptor phosphorylation, internalization, and representation. J Biol Chem 278 : 36733-36739.

37. Quillinan N, Lau EK, Virk M, von Zastrow M, Williams JT (2011) Recovery from mu-opioid receptor desensitization after chronic treatment with morphine and methadone. J Neurosci 31: 4434-4443.

38. Zhang L, Zhao H, Qiu Y, Loh HH, Law PY, et al. (2009) Src phosphorylation of micro-receptor is responsible for the receptor switching from an inhibitory to a stimulatory signal. J Biol Chem 284: 1990-2000.

39. Zhang L, Loh HH, Law PY (2013) A novel noncanonical signaling pathway for the $11 / 4$-opioid receptor. Mol Pharmacol 84: 844-853.

40. Luttrell LM, Ferguson SS, Daaka Y, Miller WE, Maudsley S, et al. (1999) Betaarrestin-dependent formation of beta2 adrenergic receptor-Src protein kinase complexes. Science 283: 655-661.

41. Filizola M, Laakkonen L, Loew GH (1999) 3D modeling, ligand binding and activation studies of the cloned mouse delta, mu; and kappa opioid receptors. Protein Eng 12: 927-942. 